\title{
LIVER FUNCTION TESTS IN HIV-1 INFECTED ASYMPTOMATIC PATIENTS AND HIV-1 AIDS PATIENTS WITHOUT HEPATOMEGALY IN LAGOS, NIGERIA
}

\author{
IOgunro, P. S., ${ }^{1}$ Oparinde, D. P., ${ }^{2}$ Okesina, A. B. \\ Department of ${ }^{1}$ Chemical Pathology/Immunology, \\ College of Health Sciences, Ladoke Akintola University of Technology \\ PMB 4400, Osogbo, Nigeria \\ Department of ${ }^{2}$ Chemical Pathology/Immunology, \\ College of Medicine, University of Ilorin, Ilorin, Nigeria
}

Correspondence to: Dr. P. S. Ogunro (E-mail:- ogunrops@yahoo.com)

\begin{abstract}
Hepatic functions were assessed by serum assays of albumin (ALB), total protein (TP), total bilirubin (TB), conjugated bilirubin (CB), serum activities of alanine transaminase (ALT), aspartate transaminase (AST), alkaline phosphatase (ALP) and gamma - glutamyl transferase (GGT) in 51 HIV 1 AIDS patients, 38 HIV-1 infected asymptomatic patients and 56 age and sex matched healthy HIV negative controls. The mean \pm SEM serum ALB concentration of $23.5 \pm 1.2$ $\mathrm{g} / \mathrm{L}$ in AIDS patients was significantly lower $(\mathrm{p}<0.001)$ than those of HIV-1 infected asymptomatic patients and healthy controls; $38.9 \pm 3.1 \mathrm{~g} / \mathrm{L}$ and $39.4 \pm 2.8 \mathrm{~g} / \mathrm{L}$ respectively. The mean $\pm \mathrm{SEM} \mathrm{TB}$ concentration of $17.8 \pm 1.3$

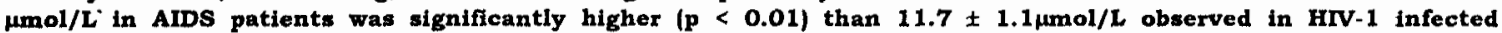
asymptomatic patients and $10.8 \pm 2.1 \mu \mathrm{mol} / \mathrm{L}$ in the controls. Similarly, there was a significant elevation (p $<0.05)$ in verum CB concentration of $6.5 \pm 0.9 \mu \mathrm{mol} / \mathrm{L}$ in AIDS patients compared to HIV-I infected patients of $3.8 \pm 1.0 \mu \mathrm{mol} / \mathrm{L}$ and controls of $3.1 \pm 0.8 \mu \mathrm{mol} / \mathrm{L}$. The mean \pm SEM ALT, AST, ALP and GGT activities (iu/L) of 48.7 $\pm 3.1,54.3 \pm 3.3$, $84.8 \pm 4.3$ and $47.5 \pm 4.1$ respectively in ArDs patients were significantly higher $(p<0.001)$ than $21.3 \pm 2.9,25.6 \pm$ $1.3,56.4 \pm 3.2$ and $25.1 \pm 1.7$ respectively observed for the same enzymes in HIV- 1 infected patients and $20.1 \pm 3.1$, $24.5 \pm 2.6,54.6 \pm 4.3$ and $24.2 \pm 2.1$ respectively in the controls. These results provide evidence to suggest that hepatic damage is greater in AIDS patients than in HIV-1 infected asymptomatic patients even in the absence of hepatomegaly. We conclude that this may be due to opportunistic infections that set in at the later part of hrv-1 infection (i.e. at AIDS stage) or increase severity of HIV. 1 infection or both
\end{abstract}

Key Words: HIV-1 infected asymptomatic patient, AIDS, Hepatic functions

\section{INTRODUCTION}

Patients infected with Human Immunodeficiency Virus (HIV), the causative agent of Acquired Immunodeficiency Syndrome (AIDS), display a broad spectrum of clinical manifestations ranging from asymptomatic state to life threatening symptomatic state characterized by opportunistic infections and malignancies (1)

The hallmark of HIV infection is the cytopathic effect on the CD4 bearing cells (Helper T4 cells) (2). Apart from these cells, other CD4 protein bearing cells such as macrophages, B-lymphocyte, microglial cells, haemopoietic stem cells, rectal mucosal cells, Kupffer cells and liver sinusoid epithelial cells are also affected (3) HIV is a pathogen that causes a variety of specific and non-specific defects in immune function that result in diverse clinical consequences. Studies in the USA and Europe (4) indicate that approximately 50\% of HIV infected patients will develop AIDS by 10 years; $75 \%$ by 15 years and $90 \%$ by 20 years (4)

In about two weeks after infection with HIV, approximately $50 \%$ of patients will develop a viral illness that may resemble glandular fever, influenza or aseptic meningitis. In more severe cases, 
hepatomegaly and raised transaminases may be detected $(5,6)$.

Hepatomegaly is a frequent finding in about two-third of AIDS patients and some abnormalities in liver function tests of HIV and AIDS patients have been reporțed $(7,8)$. The cause of this hepatomegaly has been ascribed to various mechanisms such as infection arising from HIV, hepatitis $B$, nonA non-B, sepsis, alcoholic liver disease and malnutrition (8-14). Although the presence of hepatomegaly indicates some degree of hepatocellular damage and or hepatobiliary obstruction in HIV-1 AIDS patients, it is not however clear whether hepatic pathology exists in HIV-1 infected asymptomatic and HIV-1 AIDS patients without hepatomegaly.

This study compares the biochemical indices of liver cell damage and hepatobiliary obstruction in HIV-1 infected asymptomatic and HIV-1 AIDS patients without hepatomegaly.

\section{MATERIALS AND METHOD}

The study was carried out after obtaining approval from the Ethical Committee of the Lagos University Teaching Hospital, Nigeria. Forty five AIDS patients and 38 HIV-1 infected patients were randomly selected from those seen in LUTH for this study. The HIV-1 infected asymptomatic patients consists 16 males and 22 females aged between 20-70 years from among those found seropositive by ELISA method (15) and confirmed by Western Blot (16). The full-blown HIV-I AIDS patients consist 19 males and 26 females aged between 20-70 years. Fifty six control subjects, 25 males and 31 females, were selected from healthy individuals matched for age and sex who were screened and found negative for HIV-I and II.
Subjects who had evidence of hepatitis B, non-A non-B, alcoholic liver disease, hepatomegaly, sepsis, malnutrition and those on cytotoxic drugs were excluded from the study. Screening for hepatitis was carried on each subject and control, using Wellcome ELISA kit. Those positive were excluded from the study.

About 5 milliliters of venous blood was collected from each of the subject and control and was allowed to clot and retract. Serum was obtained after centrifugation at 3,500 rpm for 10 minutes and the samples were stored frozen at $-20^{\circ} \mathrm{C}$ until analyzed. Lyophilized controls were obtained from Randox Laboratory. Analysis was carried out in batches with the aid of BECKMAN SYNCHRON (CX5 serial no 4562) autoanalyser, using appropriate control with each batch. Serum albumin was estimated based on the dye-binding method of Doumas, Watson and Biggs (17), total protein by the method of Doumas, Bayse and Carter (18), total and conjugated bilirubin by the method of Malloy and Evelyn (19), AST by the method of Karmen (20), ALT by the method of Wroblewski and LaDue (21), ALP by the method of Bassey et al (22) and GGT by the method recommended by IFCC Part 4 (23). Results obtained were subjected to statistical analysis using computer with EPI-INFO version 6.2 software. The Student's t-test was used to determine the differences between the means of the various groups.

\section{RESULTS}

Table 1 displayed the demographic characteristics of sample population while Table 2 displayed the summarized comparative mean \pm SEM of hepatic biochemical parameters in the two groups of 
subjects and the controls. The result shows a significant decrease $(p<0.001)$ in the mean serum concentration of albumin in AIDS patients when compared with healthy controls and HIV-1 infected asymptomatic patients. Also, a significant increase $(p<$ 0.0 ) in serum level of total bilirubin was observed in AIDS patients compared to HIV1 infected patients and healthy controls. Similarly, there was a significant elevation ( $p$ $<0.05$ ) in the serum level of conjugated bilirubin in AIDS patients when compared to HIV-1 infected asymptomatic patients and the controls.

The mean serum activities of ALT and AST in AIDS patients were significantly increased $(\mathrm{P}<0.001)$ when compared with those of HIV-1 infected asymptomatic patients and the controls. The ALT and AST activities in the controls were not significantly different from those of the HIV1 infected asymptomlatic individuals. The mean serum activities of ALP and GGT in AIDS patients were significantly increased $(\mathrm{P}<0.001)$ when compared with those of HIV 1 infected asymptomatic patients and controls respectively. The mean serum activities of ALP and GGT in controls were not significantly different from those of HIV$l$ infected asymptomatic individuals.

Table 1: Demographic characteristics of sample population

\begin{tabular}{|c|c|c|c|c|c|c|}
\hline Age group & Cox & & HIV. & fected & AIDS & \\
\hline (In years) & Male & Female & Male & Female & Male & Female \\
\hline $20-40$ & 12 & 15 & 9 & 10 & 10 & 14 \\
\hline $41-60$ & 9 & 12 & 5 & 8 & 8 & 10 \\
\hline$>60$ & 4 & 4 & 2 & 4 & 1 & 2 \\
\hline
\end{tabular}

Table 2: Means \pm SEM of hepatic biochemical parameterm in HV- 1 infected Patients and AIDS patients without hepatomegaly, and controls

\begin{tabular}{|c|c|c|c|c|c|}
\hline Parameter/Unit & Control & HIV-I infected & AIDS & & \\
\hline Albumin $(g / L)$ & $39.4 \pm 2.8$ & $38.9 \pm 3.1$ & $23.5 \pm 1.2$ & $\bullet$ & $* * *$ \\
\hline Total Protein $(g / L)$ & $74.3 \pm 5.1$ & $73.6 \pm 6.3$ & $72.9 \pm 4.8$ & & \\
\hline Bil. Total $(\mu \mathrm{mol} / \mathrm{L})$ & $10.8 \pm 2.1$ & $11.7 \pm 1.1$ & $17.8 \pm 1.3$ & $\leftrightarrow$ & $* *$ \\
\hline Bil. $\operatorname{Conj}(\mu \mathrm{mol} / \mathrm{L})$ & $3.1 \pm 0.8$ & $3.8 \pm 1.0$ & $6.5 \pm 0.9$ & - & $*$ \\
\hline ALT (IU/L) & $20.6 \pm 3.1$ & $21.3 \pm 2.9$ & $48.7 \pm 3.1$ & $\cdots$ & $* * *$ \\
\hline AST $(I U / L)$ & $24.5 \pm 2.6$ & $25.6 \pm 1.3$ & $54.3 \pm 3.3$ & $\bullet \bullet$ & $* * *$ \\
\hline$A L P(I U / L)$ & $54.6 \pm 4.3$ & $56.4 \pm 3.2$ & $84.8 \pm 4.3$ & $\cdots$ & $* * *$ \\
\hline GGT $(I U / L)$ & $24.2 \pm 2.1$ & $25.1 \pm 1.7$ & $47.5 \pm 4.1$ & $\leftrightarrow$ & $* * *$ \\
\hline Alb./Globulin Ratio & $39.4 / 34.9$ & $38.9 / 34.7$ & $23.5 / 49.4$ & $4 \bullet$ & $* *$ \\
\hline
\end{tabular}

\section{DISCUSSION}

In this study, the concentration of serum albumin was found to be low in AIDS patients compared to controls. This finding is similar to the study of Geffriand et al (24), who found that serum albumin was 
significantly reduced in AIDS patients. But Cello (25) and Cappell (26) reported no significant reduction in albumin concentration when AIDS patients were compared with controls. In acute liver disease, there may be little or no reduction in plasma albumin because its biological half-life is about 20 days and also the fractional clearance rate is very low (27). Apart from chronic hepatic lesions, hypoalbuminaemia found in this group of patients, may be due to increased catabolism from tissue damage, inflammation, malnutrition, malabsorption syndromes and protein loss (28). It has been observed that majority of patients with AIDS who develop diarrhoea have some degree of malabsorption (29). All the AIDS patients in our study had diarrhoea and this may have synergistically contributed to hypoalbuminaemia resulting from reduced synthetic liver function.

The observed significant reduction in the mean \pm SEM plasma albumin in AIDS patients compared to the control subjects suggests a chronic hepatic dysfunction. This is further corroborated by the significant elevation of the mean \pm SEM plasma activities of ALT and AST in AIDS patients compared to the controls and HIV-1 infected asymptomatic group. This observation is in keeping with the works of other researchers $(7,25,26,30)$, who found similarly elevated ALT and AST in AIDS patients compared with controls.

The total protein found in both HIV 1 and AIDS patients does not differ from that of the control, but there is a reversal of albumin/globulin ratio in AIDS patients with a higher globulin fraction. A similar pattern has been reported by Mohammed
(31) who noticed that AIDS patients have persistent generalized lymphadenopathy with hyperplasia of the B-lymphocytes in lymphoid follicles and polyclonal hypergammaglobulinopathy involving $\mathrm{IgG}$, IgA and rarely IgM. Similar pattern of hypergammaglobulinaemia has been confirmed in AIDS patients in Northern Nigeria (32).

Our study showed a significantly elevated serum total bilirubin and conjugated bilirubin, which may indicate problem with excretory function of the liver. Though the subjects were not clinically jaundiced, this may be a pointer to hepatic pathology involving hepatocytes and its enzymes or an increase in the rate of haemolysis or a decreased rate of delivery of unconjugated bilirubin to the liver secondary to hypoalbuminaemia in this group of subjects.

Our observation tallies with the work of Dworkin et al (33) who found that significant rises in serum ALP and total bilirubin occurs during the course of AIDS in American patients. However Astagueau et al (34) in France, Cello et al (25) and Cappell et al (26) in America, reported that jaundice was rare in AIDS patients. Serum transaminases ALT and AST activities were significantly raised in AIDS patients compared to those of the healthy individuals, this is suggestive of an increased degree of hepatocellular damage in AIDS patients. This observation has been noted in previous studies carried out on American whites and blacks $(12,25,26,30)$, and by some other workers $(24,35,36)$ who also found raised serum activities of ALT ' and AST in AIDS patients compared to healthy individuals. Opportunistic infections 
. of the liver such as Mycobacterium aviumintracellulare, Mycobacterium tuberculosis, Cytomegalovirus, Cryptococcus neoformans, and Pneumocystis carinit which are common complications in AIDS patients have been implicated as the cause of liver parenchymal cell damage (25).

Significantly elevated serum ALP and GGT observed in AIDS patients may be a pointer to a higher degree of damage that results in hepatobiliary obstruction in this group of subjects. Invasive and non-invasive diagnostic procedures have revealed and documented papillary stenosis, sclerosing cholangitis, cholecystitis as well as thickened gall bladder wall in a growing population of AIDS patients (14). All these structural abnormalities have been attributed to opportunistic infections. Our findings agree with the previous studies in America $(13,14,25,26,30,37)$, and some other parts of the world where similarly elevated ALP and GG' in AIDS patients was found $(35,36,38)$. Previous studies explained that this biochemical relationship is compatible with localized biliary obstructive lesions in liver due to localized CD4 site in the liver sinusoid epithelial cell surfaces $(39,40,41)$.

Opportunistic infections in late stage of the disease (AIDS) may likely be the cause of hepatic damage in this study however the time of onset or degree of infection was not determined to establish whether difference in findings between asymptomatic HIV-1 infected and AIDS patients are due to severity of the condition. This possibility cannot be totally ruled out.

\section{conclusion}

The significant reduction in the serum albumin is a strong pointer to the presence of chronic hepatic lesion in patients with AIDS although various other possibilities like diarrhoea were adduced in the discussion. Our result shows that hepatic lesion in AIDS patients without hepatomegaly affects both hepatocellular integrity and hepatobiliary obstruction with a greater severity than HIV-1 infected asymptomatic patients without hepatomegaly. We therefore conclude that the level of hepatic function distortion is greater in AIDS patients than in HIV-1 infected asymptomatic patients even in the absence of hepatomegaly. Further work need to be carried out to determine whether the level of distortion of hepatic function is similar in these two groups of patients in the presence of hepatomegaly.

\section{REFTRENCES}

1. Chaisson RE, Volberding PA. Clinical manifestation of HIV infection. In: Mandell $\mathrm{GL}$, Douglas and Bennett (Eds.). Principles and Practice of Infectious Diseases. $3^{\text {rd }}$ edition. Churchill Livingstone, 1991; 1059.

2. Klatzmann D, Barre Sinoussi F, Nugeyre $\mathrm{M}$, et al. Selective tropism of Lymphadenopathy- associated virus (LAV) for helper - inducer $T$ Lymphocytes. Sciences. 1984; 225 : 59 . 62

3. Castro B, Cheng-Meyer C, Evans LA, Levy SA. HIV heterogeneity and viral pathogenesis. AIDS. 1988; 2: 517-527

4. Chin J, Lwainga SK. Bulletin of World Health Organization.1991; 69(4): 000odo.

5. Gaines $\mathrm{H}$, Von Sydow M, Pehrsor PO. Clinical picture of primary HIV infection presenting a glandular fever-like illness. BMJ. 1988; 297: 1363-1368

6. Boag FC, Dean $R$, Hawkins $D A$, Lawrence AG, Gazzard BG. Abnormalities of liver function during HIV seroconversion illness. Int. J. STD AIDS. 1992; 3: 46-48

7. Ball SG. Chemical Pathology of AIDS. Ann. Clin. Biochem 1994; 31: 401-409

8. Schneiderman DJ. Hepatobiliary abnormalities of AIDS. Gastroenterol. Clin. North Am 1988; 17: 615-630.

9. Lebovics E, Thung SW, Sehaffner F, Radensky PW. The Liver in the AIDS: a clinical and histologic study. Hepatology. 1985; 5: 293-298 

The Spectrum of liver discase in the AIDS. J. Hepatol. 1986; 2: 475-484

11. Schneiderman DJ, Arenson DM, Cello JP, Mangaretten W, Weber TE. Hepatic disease in patient with AIDS. Hepatology. 1987; 7: $925-930$

12. Glasgow, et al. Clinical and pathologic findings of the liver in the Acquired Immunodeficiency Syndrome (AIDS). $A m$. J. Clin. Pathol. 1985; 83: 582-588.

13. Margulis SJ, Honig CL, Soave R, Govoni AF, Mouradian JA, Jacobson IM. Biliary tract obstruction in the AIDS. Ann. Intern Med. 1986; 105: 207-210

14. Schneiderman DJ, Cello JP, Caing FC. Papillary stenosis and sclerosing cholangitis in the acquired immunodefiency syndrome. Ann. Intern .Med. 1987; 106: 546-549

15. Centres for Disease Control and Prevention. Update: Serologic testing for antibody to human immunodeficiency virus. MMWR. 1988; 36: 833-845.

16. Centres for Disease Control, MMWR interpretation and use of the Western blot for serodiagnosis of human immunodeficiency type 1 infection. MMWR. Morb. Mortal. Wkly Rep. 1987; 38:1-7

17. Doumas BT, Watson WA, Biggs HC Albumin standards and the measurement of serum albumin with bromocresol green. Clin. Chim. Acta. 1971; 31: 87-96.

18. Doumas BT, Bayse DD, Carter RJ, et al. A candidate reference method for determination of total protein in serum. I Development and validation, Clin. Chem. 1981; 27: 1642-1650.

19. Malloy HT, Evelyn KA. The determination of bilirubin with the photoelectric colorimeter. J. Biol. Chem 1937; 119: 481-490.

20. Karmen S. A note on the spectrophotometric assay of glutamic oxaloacetic transaminase in human blood serum. J. Clin. Invest. 1955; 34: 131-135.

21. Wroblewski F, LaDue JS. Serum glutamic-pyruvic transaminase in cardiac and hepatic disease. Proc. Soc. Exp. Biol. Med.1956; 91: 569571

22. Bassey O, Lowry $\mathrm{OH}$, Brock MJ. Method for the determination of alkaline phosphatase with five cubic millimeters of serum. J. Biol.Chem.1946; 164: 321 329

23. IFCC Expert Panel on Enzymes: IFCC methods for the measurement of the catalytic concentration of enzymes Part 4. IFCC method for gamma-glutamyl transferase. J. Clin. Chem. Clin. Biochem. 1983; 21: 633-646.

24. Geffriaud, et al. Hepatic involvement in HIV-1 virus infections. Gastroenterol. Clin. Bioc. 1988; 12 (5): 465-472.
Cello JP. Acquired Immunodeficiency Syndrome Cholangiopathy: Spectrum disease. Am. J. Med. 1989; 86: 539-546

26. Cappell, et al. Clinical utility of liver biopsy in patients with serum antibodies to the HIV. Am. J. Med.1990; 88: 123130 .

27. Whitby, et al. Liver disease. Lecture Notes on Clinical Biochemistry, $5^{\text {th }}$ edition, Blackwell Scientific Publication. 1993: 105

28. Gillin, et al. Malabsorption and mucosal abnormalities of the small intestine in the AIDS. Ann. Intern. Med.1985; 102: 619-622.

29. Miller, et al. Jejunal mucosal architecture and fat absorption in male homosexuals infected with HIV. Qt. J. Med 1988; 69: 1009-1019.

30. Prufer, et al. Hepatic invokement in patients with human immunodeficiency virus infection: discrepancies between AIDS patients and those with earlier stages of infection. J. Infect. Dis. 1991; 163 (4): 866-869

31. Mohammed I. AIDS in Nigeria. An immunological perspective. Nig. J. Immunol.1990; 2: 1-3

32 Uko GP, Griffiths M, Dawkins RL, et al. IgG2 associated hypergammaglobulinaemia in some Nigerians with HIV infection. Afr. J. Med. Sci. 1994; 23: 385-388.

33 Dworkin, et al. The liver in acquired immune deficiency syndrome: Emphasis on patients with intravenou's drug abuse. Am. J. Gasroenterol.1987; 2(3): 231-236.

34 Astageau, et al. Hepatic involvement in AIDS. A retrospective clinical study in 71 patients. Ann. Med. Intern. Paris.1990, 141(5): 459-463.

35 Escartin, et al. The spectrum of liver disease in infection by the human immunodeficiency virus: a study of 50 liver biopsies. Med. Clin. Barc.1991; 97(6): 201-215

36 Orenstain, et al. Granulomatous involvement of the liver in patients with AIDS. Gut. 1985; 26(II): $1220-1225$.

37 Forbes A, Blanshard C, Gazzard B Natural history of AIDS related sclerosing cholangitis: a study of 20 cases. Gut.1993; 34: 116-121.

38 Hess, et al. Diseases of the liver and bile due to an AIDS. $Z$.

Gasroenterol.Verh. 1989; 24: 167-170

39. Castro B, Chang-Meyer C, Evans LA, Levy SA. HIV heterogeneity and viral pathogenesis. AIDS. 1988; 2: 517-527

40. Levy JA. Human immunodeficiency viruses and the pathogenesis AIDS. JAMA. 1989; 261: 2997- 2003.

41. Chang-Mayer C, et al. HIV can productively infect cultured glial cells. Proc. Natl Acad. Sci. U.S.A 1987; 84 : 3526-3530

Visit our website at http://www.ajol.info/journals/ajcem 